\title{
Primary Renal Hydatid Cyst in Children: A Case Report
}

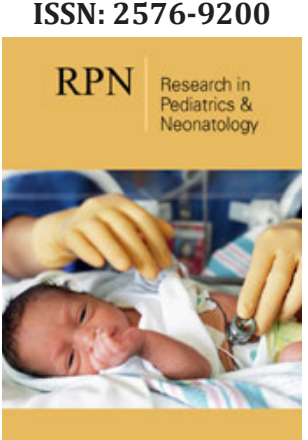

${ }^{* 1}$ Corresponding author: Asma Jabloun, Department of Peadiatric Surgery, Faculty of Medicine of Tunis, Tunisia

\section{Submission: 証 March 21, 2019}

Published: 战April 09, 2019

Volume 3 - Issue 3

How to cite this article: Asma J, Habib B, Rabiaa A, Fatma T, Riadh B M, et al Primary Renal Hydatid Cyst in Children: A Case Report. Res Pediatr Neonatol. 10(2). RPN.000562.2019.

DOI: $10.31031 /$ RPN.2019.03.000562

Copyright@ Asma Jabloun, This article is distributed under the terms of the Creative Commons Attribution 4.0 International License, which permits unrestricted use and redistribution provided that the original author and source are credited.

\author{
Asma Jabloun*1, Habib Bouthour ${ }^{1}$, Rabiaa Abdallah ${ }^{1}$, Fatma Trabelsi ${ }^{1}$, Riadh \\ Ben Malek ${ }^{1}$ and Najib Kaabar ${ }^{1}$ \\ ${ }^{1}$ Department of Peadiatric Surgery, Tunisia
}

\section{Abstract}

Echinococcosis is a prevalent zoonosis in endemic region in the world. Although Echinococcosis can be present in all parts of the human body, renal Echinococcosis is relatively uncommon compared to liver and lung localizations. Its diagnosis is sometimes problematic. There are no specific clinical symptoms or positive result in a routine laboratory analysis that will reliably confirm the diagnosis of renal echinococco. In this study, a primary right renal hydatic cyst which was found in a 7-year-old girl has been presented. The patient was treated successfully by open surgery in combination with postoperative chemotherapy with albendazole. Physicians should be aware of its clinical presentations and complications.

Keywords: Cystic; Echinococcosis; Hydatidoses; Hydatid; Renal

\section{Introduction}

Echinococcosis or hydatid cyst disease is a zoonotic infection caused by the genus Echinococcus [1]. It is a public health problem around the world. Humans are an accidental intermediate host. The most commonly affected organ in children is the liver and the lung but the disease may affect any organ [2]. Echinococcosis of the kidney is extremely rare constitutes only $2-4 \%$ of all cases of hydatid disease [3]. In children, kidney involvement by hydatid disease is very rare, constituting only $1.9 \%$ of all cases [4]. We report a peadiatric case of renal hydatid cyst disease.

\section{Case Report}

A 7-year-old girl, living in an urban area, was admitted with recurring right lumbar pain. The examination found tenderness and mobile mass in the right upper quadrant of abdomen. A right lumbar sensitivity was also found without any urinary signs. The biological assessment was normal, there was no eosinophilia. The ultrasound imaging (US) found a renal hydatidosis $(66 \times 52 \mathrm{~mm})$ (Figure 1) and computed tomography (CT) of the abdomen confirmed isolated hydatid cyst in the upper third of right kidney classified grade 2 (Figure2). No cystic or solid lesions were found in hepatic, spleen, and left kidney. Chest X Ray was normal. An indirect hemagglutination (IHA) test for Echinococcosis granulosus was negative.

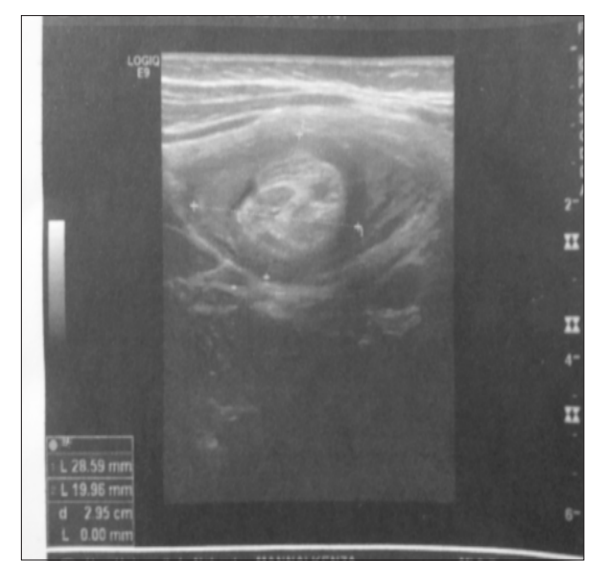

Figure 1: Abdominal ultrasound scan showing grade 3 hydatic cysts in the right kidney. 


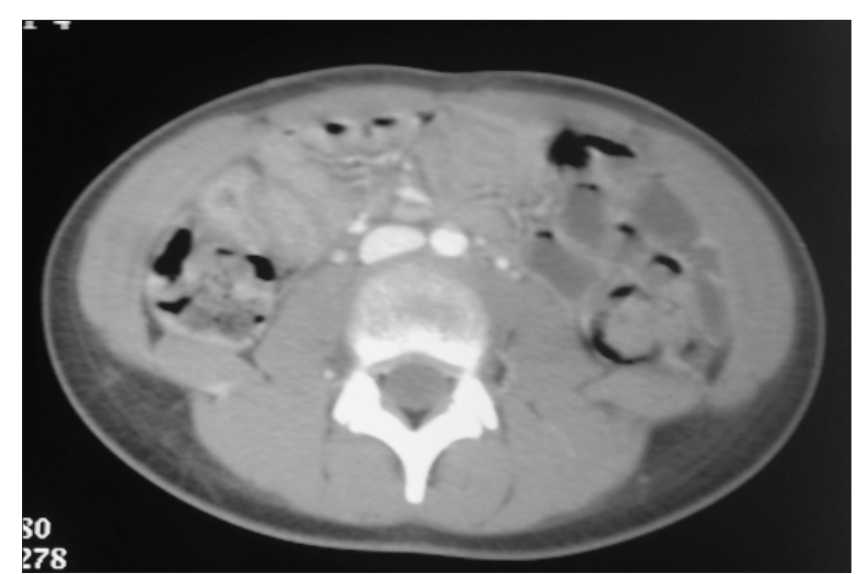

Figure 2: Abdominal CT scan showing renal hydatic cyst in the upper third of the right .

The patient was managed by right lumbotomy, after injection of $30 \% \mathrm{NaCl}$ solution, the germinative membrane was removed (Figure 3), a resection of the neighboring tissues was also realized, the fluid content of the cyst was aspirated and the cavity was filled with $30 \% \mathrm{NaCl}$ solution. The patient has received albendazolebased medical treatment for six months later. The evolution was good with a follow up of three year.

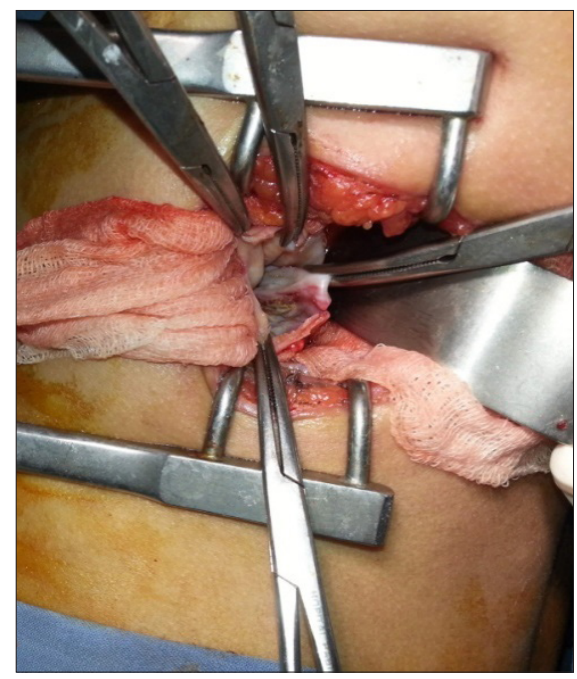

Figure 3: Preoperative view after removing germinative membrane of renal hydatid cyst.

\section{Discussion}

Renal Echinococcosis, also called hydatid cyst of the kidney, is an acquired disease of the kidney, caused by the larval stage of Echinococcus granulosus [1]. Kidney involvement is usually observed in the form of a single cyst located at the level of the renal cortex [4]. Symptoms vary depending on the size, extension, and location of the cyst [5]. Patients may be asymptomatic for long periods of time [2]. Some may present with a palpable mass, like in our case, and could be misinterpreted as a renal tumor. It should be considered in the differential diagnosis of renal cystic lesions [6]. Rarely some patient present with a history of Hydatiduria, a pathognomonic presentation of the disease, which observed in only
$3-18 \%$ of the patients when the cyst ruptures into the collecting system passing [7].

Therefore, radiological imaging studies played a crucial role in the preoperative diagnosis of this hydatid disease. Ultrasound (US) and computed tomography (CT) identify the loculated nature of the lesion and may demonstrate a floating membrane, which confirms the diagnosis. computed tomography is more sensitive than US imaging, evidenced by its ability to detect calcifications, it requires harmful ionizing radiation [8]. magnetic resonance imaging (MRI) is preferable since it delivers high-resolution images without this high dose of radiation, of importance in children [9]. Hypointense rim and multi cystic appearance is distinctive in MRI which also delineates the anatomy well. Intravenous urogram should be done to rule out a communication with renal ductal system $[7,8]$.

Serology may be helpful and include immuno-electrophoresis, immuno-hemagglutination test, and complement fixation test [1]. However, none of the serologic tests are pathognomonic of renal hydatid cysts [9]. The gold standard therapy for the disease is mainly surgical, in view of the catastrophic complications that a cyst rupture can cause [7]. Conservative medical management with oral albendazole is unreliable, being successful in only $40 \%$ of cases $[4,10]$. Less invasive methods such as echo or CT-guided percutaneous drainage of the cyst with suction and instillation of saline solution or alcohol may be prescribed in select cases, but it is successful in only $70 \%$ of cases of unilocular cysts [7]. Surgical management consists of various options. Both open and laparoscopic methods have been described in the literature [3]. Depending on the size of the cyst, a partial or a radical nephrectomy is performed in adult. In children conservative surgery is preferred and the cyst alone may be excised [11]. Total excision consists of either wedge resection or partial nephrectomy and partial excision includes partial pericystectomy followed by capitonnage, re-approximation of the pericyst or marsupialization [4]. Renal sparing surgery by way of partial excision is possible and is the most adapted treatment whenever possible preceded by the injection of scolicidal agents into the cyst $[2,4,12]$ No intervention is needed when the cyst walls are calcified [12]. Conventionally, it is recommended to start the patient on a course of oral albendazole after surgery [10].

\section{Conclusion}

The renal hydatid cyst in children constitutes a very rare localization. It has variable and polymorph symptomatology which is rarely specific. The Renal hydatid cyst has to be evoked in all renal cystic lesions, especially in endemic regions like Tunisia. The surgical approach remains the treatment of choice; particularly should be mostly conservative.

\section{References}

1. Agudelo NI, Brunetti E, Closkey C (2016) Cystic Echinococcosis. Journal of clinical microbiology 54(3): 518-523.

2. Moscatelli G, Moroni S, Freilij H, Salgueiro F, García F, et al. (2013) A fiveyear-old child with renal hydatidosis. The American Journal of Tropical Medicine and Hygiene 89(3): 554-556. 
3. Rexiati M, Mutalifu A, Azhati B, Wang W, Yang H, et al. (2014) Diagnosis and surgical treatment of renal hydatid disease: a retrospective analysis of 30 cases. PloS One 9(5): e96602.

4. Sarmast AH, Sherwani AY, Dangroo SA, Wani MS, Hamid A, et al. (2014) An isolated renal hydatid cyst in a 6-year-old child: A rare case report. J Res Med Sci 19(3): 279-281.

5. Parry AH, Wani AH, Feroz I (2018) Renal hydatid cyst presenting as an intrarenal-pelvic mass. Indian J Urol 34(4): 303-304.

6. Gadelkareem RA, Elqady AA, Elshafy SK, Imam H, Abolella HA (2018) Isolated renal hydatid cyst misdiagnosed and operated as a cystic renal tumor. Med Princ Pract 27(3): 297-300.

7. Hamidi A, Enshaei A, Pourreza F, Esmaeili S, Madani M (2015) Macroscopic hydatiduria: an uncommon pathognomonic presentation of renal hydatid disease. Iran J Public Health 44(9):1283-1287.
8. Bhaya A, Shinde AP (2015) Isolated renal hydatid presenting as a complex renal lesion followed by spontaneous hydatiduria. World Journal of Radiology 7(7): 180-183.

9. Polat G, Pirimoglu B, Sade R, Kantarci M (2018) Paediatric renal hydatid cyst. QJM: Monthly Journal of the Association of Physicians 111(7): 497498.

10. Soares AT, Couto C, Cabral MJ, Carmona L, Vieira I (2016) Renal hydatid cyst: Medical treatment. J Bras Nefrol 38(1): 123-126.

11. Tirnea L, Minciu R, Olariu TR, Dumitrascu V, Neghina AM, et al. (2014) A rare case of renal hydatidosis in a child with congenital solitary kidney. Asian Pacific Journal of Tropical Medicine 7(8): 671-672.

12. Ucar M, Akgul A, Celik F, Kilic N (2016) Excisional treatment of renal hydatid cyst mimicking renal tumor with diode laser technique: A case report. J Pediatr Urol 12(4): 264.

For possible submissions Click below: 